\title{
Stereotactic body radiotherapy for adenoid cystic carcinoma metastatic to the lung: a case report
}

\author{
Daijiro Kobayashi ${ }^{1,2^{*}}\left(\mathbb{0}\right.$, Takanori Abe ${ }^{3}$, Jun-ichi Saitoh ${ }^{4}$, Takahiro Oike ${ }^{5}$, Hiro Sato ${ }^{5}$, Atsushi Musha ${ }^{6}$, \\ Tatsuji Mizukami ${ }^{4}$, Tsuneo Shimizu', Takashi Nakano ${ }^{7}$ and Tatsuya Ohno 5,6
}

\begin{abstract}
Background: Adenoid cystic carcinoma (ACC) is a rare malignant tumor involving mostly the head and neck region, and frequently the salivary glands. The development of lung metastasis after treatment of the primary tumor is a common occurrence in ACC. Although lung metastases show a slow rate of growth, approximately $10 \%$ of patients die from distant metastases. The radioresistance of ACC limits the efficacy of conventional radiotherapy for lung metastases, and the optimal dose remains to be determined. Stereotactic body radiotherapy (SBRT) using CyberKnife can deliver a high dose to the lung tumor, while sparing the surrounding normal lung tissues, leading to favorable local control in non-squamous cell lung cancer and metastatic lung tumors. We report a case of lung metastases from ACC treated successfully with SBRT using CyberKnife.
\end{abstract}

Case presentation: A 76-year-old Japanese man with ACC who was treated with carbon ion radiotherapy for a primary oropharynx tumor presented with three metastatic lesions in the lung. The tumor masses were located in the right upper, right lower, and left lower lobes of the lungs. Surgical resection was not indicated because of the presence of multiple tumors. The patient underwent SBRT at $60 \mathrm{~Gy}$ in 10 sequential fractions for each tumor. The biologically effective dose based on an alpha/beta ratio of 2 Gy was 240 Gy per tumor. The percentage of the total lung volume irradiated with $>20$ Gy was $4.9 \%, 3.2 \%$, and $2.6 \%$ for each tumor. The patient developed acute radiation pneumonitis during the initial therapy, which resolved at 6 months after the CyberKnife treatment. At 21 months after the first Cyberknife treatment, three tumors showed no signs of recurrence. No late toxicity was observed.

Conclusions: SBRT using CyberKnife is an effective and feasible approach to the management of multiple lung metastases of ACC.

Keywords: Adenoid cystic carcinoma, Lung metastases, Stereotactic body radiotherapy, Radiation pneumonitis, Case report

\section{Background}

Adenoid cystic carcinoma (ACC) is a rare malignant tumor arising mostly in the head and neck region that commonly involves the salivary glands [1]. The standard

*Correspondence: dkobayashi1988@gunma-cc.jp

${ }^{1}$ CyberKnife Center, Kanto Neurosurgical Hospital, 1120 Dai, Kumagaya, Saitama 360-0804, Japan

Full list of author information is available at the end of the article treatment for primary ACC is surgery in most patients [1]. Approximately $40-60 \%$ of patients with ACC develop distant metastases at $\geq 10$ years after diagnosis $[2,3]$. The most frequent site of distant metastases is the lung [4], and distant metastasis accounts for approximately $10 \%$ of the mortality from ACC [1]. Lung metastases progress at a slow rate, and some patients survive for several years if the local disease is controlled effectively. Solitary original author(s) and the source, provide a link to the Creative Commons licence, and indicate if changes were made. The images or other third party material in this article are included in the article's Creative Commons licence, unless indicated otherwise in a credit line to the material. If material is not included in the article's Creative Commons licence and your intended use is not permitted by statutory regulation or exceeds the permitted use, you will need to obtain permission directly from the copyright holder. To view a copy of this licence, visit http://creativecommons.org/licenses/by/4.0/. The Creative Commons Public Domain Dedication waiver (http://creativeco mmons.org/publicdomain/zero/1.0/) applies to the data made available in this article, unless otherwise stated in a credit line to the data. 
metastatic tumors can be resected by surgery. Systemic chemotherapy has shown limited benefits in ACC [5].

Although radiotherapy is used in the treatment of lung metastasis, the radioresistant nature of ACC limits its efficacy [6]. Dose escalation increases the probability of local control (LC) but also increases the risk of severe lung toxicity. Stereotactic body radiotherapy (SBRT) is a treatment option for early-stage lung tumors [7]. CyberKnife (Accuray, Sunnyvale, CA, USA) is a type of SBRT that provides excellent dose localization, thereby minimizing the radiation exposure to normal tissues. The efficacy of the method for early-stage lung cancers has been widely reported [7]. Positive results of CyberKnife treatment have been reported in primary and metastatic lung cancers; however, its effect on the clinical course of multiple lung metastases from ACC has not been investigated. Assessing the incidence of acute and late lung toxicities associated with CyberKnife treatment and exploring tumor control aspects are thus important. Here, we present a case of ACC lung metastases successfully treated with CyberKnife.

Table 1 Treatment data

\begin{tabular}{|c|c|c|c|}
\hline Treatment number & $1 \mathrm{st}$ & 2nd & $3 r^{*}$ \\
\hline Tumor location & $\begin{array}{l}\text { Right } \\
\text { upper } \\
\text { lung } \\
\text { lobe }\end{array}$ & $\begin{array}{l}\text { Right } \\
\text { lower } \\
\text { lung } \\
\text { lobe }\end{array}$ & $\begin{array}{l}\text { Left lower } \\
\text { lung } \\
\text { lobe }\end{array}$ \\
\hline Tumor volume (cc) & 18.5 & 13.0 & 12.5 \\
\hline No. of beams & 65 & 71 & 90 \\
\hline Conformity index & 1.09 & 1.33 & 1.18 \\
\hline Homogeneity index & 1.45 & 1.54 & 1.61 \\
\hline Prescribed dose for D95 (Gy) & 60 & 60 & 60 \\
\hline Prescribed dose for D95 (Gy(EQD2)) & 80 & 80 & 80 \\
\hline Dmax (Gy) & 87.0 & 92.3 & 96.8 \\
\hline V20 for lung (\%) & 4.9 & 3.2 & 2.6 \\
\hline
\end{tabular}

*In the third treatment, the treatment dose was prescribed for the planning target volume (PTV). PTV had margins of $2 \mathrm{~mm}$ added around the gross tumor volume

\section{Case presentation}

A 76-year-old Japanese man with right oropharynx ACC presented at a general hospital. Computed tomography (CT) detected masses of $23 \times 19 \mathrm{~mm}$ on the right upper lung lobe, $14 \times 12 \mathrm{~mm}$ on the right lower lung lobe, and $15 \times 14 \mathrm{~mm}$ on the left lower lung lobe. ${ }^{18} \mathrm{~F}$-fluorodeoxyglucose positron emission tomography (FDG-PET) revealed abnormal accumulation in the lung tumors. The patient was diagnosed with T3NOM1, stage IVC ACC of the right oropharynx with lung metastases. Despite the lung metastasis, a favorable long-term prognosis was possible after control of the primary tumor. Radical surgery was not indicated for reasons related to functional preservation, and the patient received carbon ion (C-ion) radiotherapy for the primary tumor. The total dose was 64 Gy (relative biological effectiveness) delivered in 16 fractions. After 30 months, there was no recurrence of the primary lesion; however, the metastatic lung tumors had increased in size. The masses had grown to $32 \times 30$ $\mathrm{mm}$ on the right upper lung lobe, $31 \times 25 \mathrm{~mm}$ on the right lower lung lobe, and $18 \times 17 \mathrm{~mm}$ on the left lower lung lobe (Fig. 1). The patient consented to sequential treatment with CyberKnife for multiple lung metastases (Table 1). CT images of $1 \mathrm{~mm}$ thickness were acquired to plan the treatment. Respiratory migration was assessed by four-dimensional CT. The gross tumor volume (GTV) was delineated based on thin-slice CT images. The clinical target volume (CTV) was identical to the GTV (CTV $=$ GTV). The planning target volume (PTV) included 2 $\mathrm{mm}$ margins surrounding the CTV. The organs at risk (OARs; lung, spinal cord, heart, and skin) were outlined on the treatment planning CT scan and dose-volume histogram analysis. D95 was defined as the minimum dose covering $95 \%$ of the GTV for the first and the second CyberKnife treatments or the PTV for the third CyberKnife treatment. The dose prescribed for the PTV was used for the third treatment because of its small size. The patient received a total dose of 60 Gy in 10 fractions of D95. The treatment was planned using the MultiPlan System (Accuray). The composite dose distribution

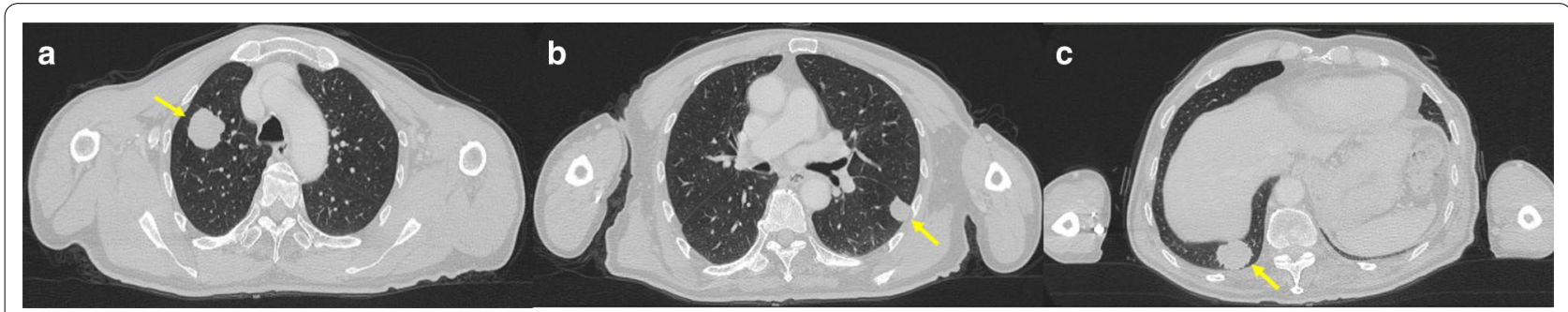

Fig. 1 Computed tomography images of metastatic adenoid cystic carcinoma of the lung before Cyberknife: a right upper lung, $\mathbf{b}$ left lower lung, and $\mathbf{c}$ right lower lung. Arrows indicate tumors 


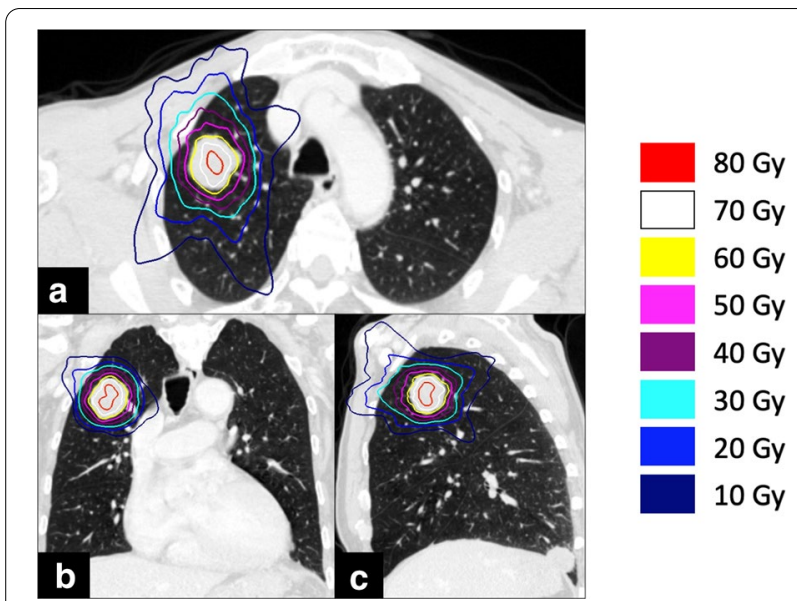

Fig. 2 Dose distribution of the CyberKnife treatment for the right upper lung tumor: a axial image, b coronal image, and c sagittal image

Table 2 Timeline

\begin{tabular}{ll}
\hline The event & Timeline \\
\hline Initial presentation & $T=0$ \\
Radiological investigations (CT scan and MRI) & $T=1$ month \\
Carbon ion radiotherapy for the primary tumor & $T=2$ months \\
Increase in the size of metastatic lung tumors & $T=32$ months \\
First CyberKnife for right upper lung tumor & $T=32$ months \\
Radiation pneumonitis grade 1 & $T=35$ months \\
Second CyberKnife for right lower lung tumor & $T=38$ months \\
Third CyberKnife for left lower lung tumor & $T=47$ months \\
No signs of recurrence or no adverse events & $T=53$ months \\
\hline
\end{tabular}

$C T$ computed tomography, $M R I$ magnetic resonance imaging

is depicted in Fig. 2. The treatment data for the first CyberKnife administration are summarized in Table 2. Conformity and homogeneity indices were calculated according to the following formulas [8]:

Conformity index $=\mathrm{TV}_{\mathrm{RI}} / \mathrm{TV}$

Homogeneity index $=$ maximum dose/prescribed dose $\mathrm{TV}_{\mathrm{RI}}=$ target volume covered by the reference isodose $\mathrm{TV}=$ target volume

The conformity and homogeneity indices were 1.09 and 1.45 , respectively.

At 3 months after the first CyberKnife treatment, the patient developed acute radiation pneumonitis, which was classified as grade 1 based on the Common Terminology Criteria for Adverse Events, version 4.0 (Fig. 3). The radiation pneumonitis remained at grade 1 for 6 months after CyberKnife treatment. After confirming that the pulmonary fibrosis and inflammatory reaction had stabilized, the second and third tumors in the right and left lower lung lobes were treated at 6 and 15 months after the first CyberKnife treatment, respectively. The patient developed grade 1 pleural effusion after the second CyberKnife session, whereas no adverse events were observed after the third treatment.

There were no chronic adverse events resulting from any of the CyberKnife treatments. Other adverse events, such as esophagitis, rib fractures, pleuritic pain, or bronchial fistula, were not observed. CT or FDG-PET/CT did not detect any signs of recurrence at 21 months after the first CyberKnife session or at 6 months after the third CyberKnife treatment.

\section{Discussion and conclusions}

Patients with ACC may develop distant metastases late in the course of the disease without recurrence of the primary tumor [3]. If the local tumor is controlled, the cause-specific survival decreases in patients with distant metastases [1]. Among patients with head and neck ACC who are treated with $\mathrm{C}$-ion radiotherapy, $15 \%$ develop lung metastasis [9]. Girelli et al. reported that the extent of resection of metastatic lung tumors contributes significantly to a longer overall survival (OS) in patients with ACC; the 5-year OS rate is $69.5 \%$ after complete resection and $51.3 \%$ after incomplete resection $(p=0.004)$ [10]. The study underscores the importance of controlling lung metastases to improve the OS of ACC patients. In the present case, although the primary oropharynx $\mathrm{ACC}$ was controlled by $\mathrm{C}$-ion radiotherapy, the size of the three metastatic lung tumors increased gradually. Local treatment for multiple lung metastases was sequentially attempted using SBRT based on the efficacy of this therapy for the treatment of lung tumors [7].

The optimal dose regimen for lung metastasis of ACC remains to be determined. Previous studies suggest that 60 Gy (EQD2) is insufficient for the LC of primary pulmonary ACC (Table 3) [11-18]. In addition, the results of conventional radiotherapy for ACC of the head and neck remain inadequate, with a 5-year LC of 56\% [19]. Current data indicate that dose escalation is needed to improve LC. However, in conventional radiotherapy, dose escalation also increases the risk of radiation pneumonitis. Other potential adverse events observed after shortterm follow-up include grade 1 bronchial stricture and grade 3 esophagitis [11, 18]. Grade 1 bronchial stricture was observed after intensity-modulated radiotherapy with a total dose of 54 Gy delivered in 30 fractions. The biologically effective dose determined by assuming an alpha/beta ratio of 2 Gy (BED2Gy) was 102.6 Gy. Grade 3 esophagitis was observed after concurrent chemoradiotherapy with a total dose of 65 Gy delivered in 35 fractions (BED2Gy $=125.4 \mathrm{~Gy}$ ) and platinum chemotherapy three times per week. CyberKnife can achieve 


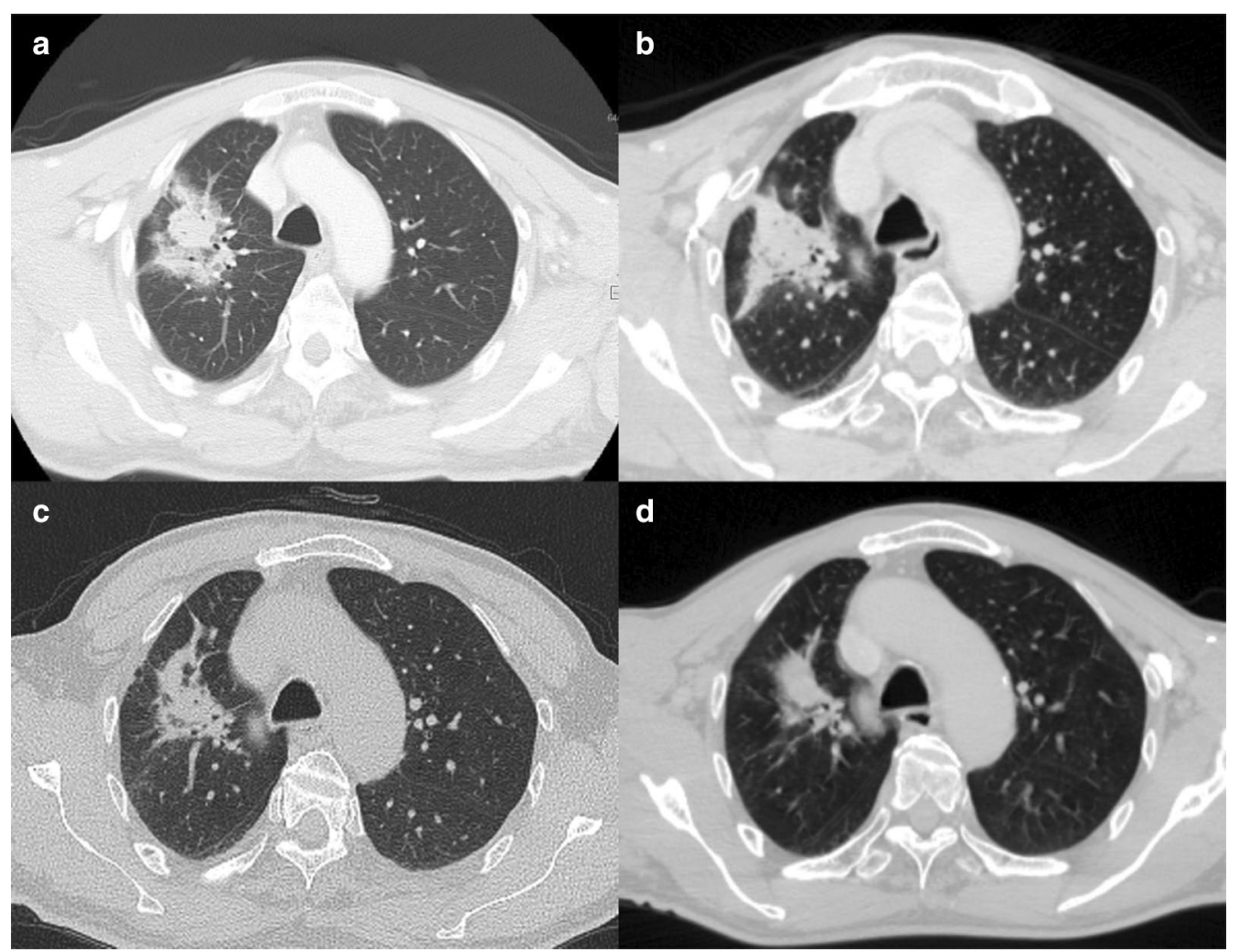

Fig. 3 Radiographical course of radiation pneumonitis developed after CyberKnife treatment of the right upper lung tumor. The extent of radiation pneumonitis was limited and it has remained stable for 21 months. a 3 months, b 6 months, c 15 months, and d 21 months after CyberKnife

Table 3 Review of the literature on radiotherapy outcomes of pulmonary ACC

\begin{tabular}{|c|c|c|c|c|c|c|}
\hline Authors & No. of patients & $\begin{array}{l}\text { Radiotherapy dose, } \\
\text { BED2Gy }\end{array}$ & Follow-up (months) & Combination therapy & Treatment outcome & Adverse events \\
\hline Bhandari V [11] & 1 & 54 Gy/30fr., $102.6 \mathrm{~Gy}$ & 8 & - & $\begin{array}{l}\text { No evidence of } \\
\text { recurrence }\end{array}$ & $\begin{array}{l}\text { Bronchial stricture } \\
\text { grade } 1\end{array}$ \\
\hline Das S [13] & 1 & 66 Gy/33 fr., $132 \mathrm{~Gy}$ & 38 & - & Local recurrence & NR \\
\hline Haresh KP [14] & 1 & 60 Gy/30 fr., 120 Gy & 19 & - & $\begin{array}{l}\text { No evidence of } \\
\text { recurrence }\end{array}$ & NR \\
\hline Kanematsu T [15] & 5 & $\begin{array}{l}\text { 50-70 Gy (median } \\
60 \text { Gy), } \\
100-140 \text { Gy (median } \\
120 \text { Gy) }\end{array}$ & NR & - & $\begin{array}{l}\text { Local recurrence in } \\
\text { all five cases (5-year } \\
\text { OS, 40\%; 10-year } \\
\text { OS, 0\%) }\end{array}$ & NR \\
\hline Kim B [16] & 1 & 66 Gy/33 fr., $132 \mathrm{~Gy}$ & 20 & $\begin{array}{l}\text { Paclitaxel, cisplatin, } \\
\text { docetaxel, gefitinib }\end{array}$ & $\begin{array}{l}\text { Dead without local } \\
\text { recurrence }\end{array}$ & $\begin{array}{l}\text { Radiation pneumonitis } \\
\text { grade } 1\end{array}$ \\
\hline Lee JH [17] & 12 & 60 Gy/30 fr., 120 Gy & 8-167 (median 59) & - & $\begin{array}{l}5 \text { year OS, 54\%; } \\
\quad 10 \text {-year OS, 27\% }\end{array}$ & NR \\
\hline Liu J [18] & 1 & $\begin{array}{l}65 \mathrm{~Gy} / 35 \mathrm{fr} .+ \text { endo- } \\
\text { bronchial boost } \\
10 \mathrm{~Gy} / 1 \mathrm{fr} ., 125.4 \mathrm{~Gy} \\
+60 \mathrm{~Gy}\end{array}$ & 90 & Cisplatin & Local recurrence & $\begin{array}{l}\text { Esophagitis grade } 3 \text {, } \\
\text { skin reaction grade } \\
\text { 1, and bronchial } \\
\text { stricture grade } 1\end{array}$ \\
\hline
\end{tabular}

fr. fractions, $B E D$ biologically equivalent dose, $O S$ overall survival, $L C$ local control, $N R$ not reported

high-dose irradiation to metastatic ACC of the lung while sparing the surrounding normal lung tissues [20], which improves the control rate. Franzes et al. reported good
LC following SBRT for oligometastatic salivary gland cancer involving ACC [21]. They used 20-54 Gy in 1-5 fractions $(\mathrm{BED} 2 \mathrm{~Gy}=94.5-345.6 \mathrm{~Gy})$. In the present 
study, BED2Gy was 240.0 Gy after administration of 60 Gy in 10 fractions. The dose concentration of CyberKnife is an important consideration. We used prescribed doses to the D95, and the dose to the central PTV was $86.95 \mathrm{~Gy}$ $(\mathrm{BED} 2 \mathrm{~Gy}=465.0 \mathrm{~Gy})$. The high doses of radiation used by CyberKnife allow the delivery of a high BED2Gy to the center of the tumor. In the present case, the high BED2Gy might have contributed to the control of the three tumors at the time of the study.

Radiation pneumonitis is a common adverse event associated with radiotherapy for lung cancer. In cases of SBRT for multiple metastatic lesions, severe radiation pneumonitis may lead to treatment-related death, and minimizing its occurrence is thus important. The percentage of total lung volume irradiated with $>20$ Gy (V20Gy) is correlated with the incidence of radiation pneumonitis [22]. In the present study, the V20Gy(EQD2) values were $4.9 \%, 3.2 \%$, and $2.6 \%$ at the first, second, and third treatments, respectively. These values are sufficient to lower the risk of radiation pneumonitis. Certain factors are associated with increased toxicity, such as centrally located tumors, chemotherapy, and target diameters [23]. If these factors are present, it may be beneficial to increase the number of fractions or decrease the prescribed dose. Pulmonary fibrosis, which is a common response to large doses per fraction in SBRT [24], can make it difficult to assess tumor recurrence and late adverse effects. In the present case, $\mathrm{CT}$ and blood tests were performed after the initial treatment. Figure 3 shows the radiographical course of radiation pneumonitis and the limitations in the management of multiple lung metastases after CyberKnife; for instance, LC could not be evaluated due to fibrosis. Thus, FDG-PET/CT imaging would help evaluate the metabolic complete response. Twenty-one months have elapsed since the first treatment, and severe pneumonitis has not occurred. These results suggest that sequential SBRT for multiple lesions can be performed safely with appropriate follow-up periods between treatments.

In conclusion, SBRT using CyberKnife is a feasible treatment for multiple lung metastases of ACC. Although a longer follow-up is necessary to determine the optimal dosing and long-term prognosis, the technique could serve as an effective option to manage lung metastases of ACC.

\footnotetext{
Abbreviations

ACC: Adenoid cystic carcinoma; LC: Local control; SBRT: Stereotactic body radiotherapy; $\mathrm{CT}$ : Computed tomography; $\mathrm{C}$-ion radiotherapy: Carbon ion radiotherapy; GTV: Gross tumor volume; CTV: Clinical target volume; PTV: Planning target volume; OARs: Organs at risk; OS: Overall survival; BED10: The biologically effective dose, assuming the alpha/beta ratio to be 10 .
}

Acknowledgements Not applicable.

\section{Authors' contributions}

All listed authors contributed to the original manuscript. The study was coordinated by DK and TA. Patient clinical data collection was performed by DK. Data analysis was performed by DK. The manuscript was prepared by DK and TA. Corrections and/or improvements were suggested by JS, TO, HS, AM, TM, TS, TN, and TO. All authors read and approved the final manuscript.

\section{Funding}

There was no funding for this study.

\section{Availability of data and materials}

The data generated and analyzed in the current study are not publicly available due to the personal patient data included, but are available from the corresponding author on reasonable request.

\section{Declarations}

\section{Ethics approval and consent to participate}

This retrospective study was approved by the institutional review board. The trial is registered in the University Hospital Medical Information Network Clinical Trials Registry (UMIN-CTR; number UMIN000032875). Individual patient consent was waived due to the retrospective nature of the study.

\section{Consent for publication}

Written informed consent was obtained from the patient for publication of this case report and any accompanying images. A copy of the written consent is available for review by the Editor-in-Chief of this journal.

\section{Competing interests}

The authors declare that they have no competing interests.

\section{Author details}

${ }^{1}$ CyberKnife Center, Kanto Neurosurgical Hospital, 1120 Dai, Kumagaya, Saitama 360-0804, Japan. ${ }^{2}$ Department of Radiation Oncology, Gunma Prefectural Cancer Center, 617-1 Takahayashi-nishicho, Ota, Gunma 373-8550, Japan. ${ }^{3}$ Department of Radiation Oncology, Saitama Medical University International Medical Center, 1397-1 Yamane, Hidaka, Saitama 350-1298, Japan. ${ }^{4}$ Division of Radiation Oncology, Department of Radiology, Faculty of Medicine, Academic Assembly, University of Toyama, 2630 Sugitani, Toyama, Toyama 930-0194, Japan. ${ }^{5}$ Department of Radiation Oncology, Gunma University Graduate School of Medicine, 3-39-22 Showa-machi, Maebashi, Gunma 371-8511, Japan. ${ }^{6}$ Gunma University Heavy Ion Medical Center, 3-39-22 Showa-machi, Maebashi, Gunma 371-8511, Japan. ${ }^{7}$ National Institute of Radiological Sciences, National Institute for Quantum and Radiological Science and Technology, 4-9-1 Anagawa, Inage, Chiba 263-8555, Japan.

Received: 28 December 2020 Accepted: 12 March 2021

Published online: 11 April 2021

\section{References}

1. Spiro RH, Huvos AG, Strong EW. Adenoid cystic carcinoma of salivary origin. A clinicopathologic study of 242 cases. Am J Surg. 1974;128:512-20.

2. Fordice J, Kershaw C, El-Naggar A, Goepfert H. Adenoid cystic carcinoma of the head and neck: predictors of morbidity and mortality. Arch Otolaryngol Head Neck Surg. 1999;125:149-52.

3. Terhaard CH, Lubsen $\mathrm{H}$, Van der Tweel I, Hilgers FJ, Eijkenboom WM, Marres HA, Tjho-Heslinga RE, de Jong JM, Roodenburg JL, Dutch H, et al. Salivary gland carcinoma: independent prognostic factors for locoregional control, distant metastases, and overall survival: results of the Dutch head and neck oncology cooperative group. Head Neck. 2004;26:681-93.

4. van der Wal JE, Becking AG, Snow GB, van der Waal I. Distant metastases of adenoid cystic carcinoma of the salivary glands and the value of diagnostic examinations during follow-up. Head Neck. 2002;24:779-83. 
5. Laurie SA, Ho AL, Fury MG, Sherman E, Pfister DG. Systemic therapy in the management of metastatic or locally recurrent adenoid cystic carcinoma of the salivary glands: a systematic review. Lancet Oncol. 2011;12:815-24.

6. Vikram B, Strong EW, Shah JP, Spiro RH. Radiation therapy in adenoidcystic carcinoma. Int J Radiat Oncol Biol Phys. 1984;10:221-3.

7. Chang JY, Senan S, Paul MA, Mehran RJ, Louie AV, Balter P, Groen HJ, McRae SE, Widder J, Feng L, et al. Stereotactic ablative radiotherapy versus lobectomy for operable stage I non-small-cell lung cancer: a pooled analysis of two randomised trials. Lancet Oncol. 2015;16:630-7.

8. Feuvret L, Noel G, Mazeron JJ, Bey P. Conformity index: a review. Int J Radiat Oncol Biol Phys. 2006;64:333-42.

9. Sulaiman NS, Demizu Y, Koto M, Saitoh Jl, Suefuji H, Tsuji H, Ohno T, Shioyama Y, Okimoto T, Daimon T, et al. Multicenter study of carbon-ion radiation therapy for adenoid cystic carcinoma of the head and neck: subanalysis of the Japan Carbon-Ion Radiation Oncology Study Group (J-CROS) Study (1402 HN). Int J Radiat Oncol Biol Phys. 2018;100:639-46.

10. Girelli L, Locati L, Galeone C, Scanagatta P, Duranti L, Licitra L, Pastorino U. Lung metastasectomy in adenoid cystic cancer: is it worth it? Oral Oncol. 2016;65:114-8.

11. Bhandari V, Ladia DD, Kausar M, Varma A. Definitive radiotherapy for inoperable adenoid cystic carcinoma of the trachea: a rare case report. Lung India. 2017;34:73-5.

12. Bittner N, Koh WJ, Laramore GE, Patel S, Mulligan MS, Douglas JG. Treatment of locally advanced adenoid cystic carcinoma of the trachea with neutron radiotherapy. Int J Radiat Oncol Biol Phys. 2008;72:410-4.

13. Das S, Dorairaja Y, Kuppusamy A. Adaptive radiotherapy in a case of adenoid cystic carcinoma of bronchus and its favourable impact on treatment outcome: a case report. Rep Pract Oncol Radiother. 2017;22:482-4.

14. Haresh KP, Prabhakar R, Rath GK, Sharma DN, Julka PK, Subramani V. Adenoid cystic carcinoma of the trachea treated with PET-CT based intensity modulated radiotherapy. J Thorac Oncol. 2008;3:793-5.

15. Kanematsu T, Yohena T, Uehara T, Ushijima C, Asoh H, Yoshino I, Ichinose Y. Treatment outcome of resected and nonresected primary adenoid cystic carcinoma of the lung. Ann Thorac Cardiovasc Surg. 2002;8:74-7.

16. Kim B. Palliative radiotherapy in a patient with pulmonary adenoid cystic carcinoma. Cancer Res Treat. 2007;39:185-8.
17. Lee JH, Jung EJ, Jeon K, Koh WJ, Suh GY, Chung MP, Kim H, Kwon OJ, Shim YM, Kim J, et al. Treatment outcomes of patients with adenoid cystic carcinoma of the airway. Lung Cancer. 2011;72:244-9.

18. Liu J, Hau E, Links M, Graham PH. Adenoid cystic carcinoma of the lung: Response to tamoxifen after chemoradiation. Asia Pac J Clin Oncol. 2016;12:e352-5.

19. Mendenhall WM, Morris CG, Amdur RJ, Werning JW, Hinerman RW, Villaret DB. Radiotherapy alone or combined with surgery for adenoid cystic carcinoma of the head and neck. Head Neck. 2004;26:154-62.

20. Kobayashi N, Abe T, Noda SE, Kumazaki YU, Hirai R, Igari M, Aoshika T, Saito S, Ryuno Y, Kato S. Stereotactic body radiotherapy for pulmonary oligometastasis from colorectal cancer. In Vivo. 2020;34:2991-6.

21. Franzese $C A-O$, Ingargiola $R$, Tomatis $S$, lacovelli NA, Beltramo G, Franco P, Bonomo P, Zanetti IB, Argenone A, Cante D, et al. Metastatic salivary gland carcinoma: a role for stereotactic body radiation therapy? A study of AIRO-Head and Neck working group. Oral Dis. 2020. https://doi.org/10. 1111/odi.13755.

22. Tsujino K, Hirota S, Endo M, Obayashi K, Kotani Y, Satouchi M, Kado T, Takada Y. Predictive value of dose-volume histogram parameters for predicting radiation pneumonitis after concurrent chemoradiation for lung cancer. Int J Radiat Oncol Biol Phys. 2003;55:110-5.

23. Timmerman R, McGarry R, Yiannoutsos C, Papiez L, Tudor K, DeLuca J, Ewing M, Abdulrahman R, DesRosiers C, Williams M, et al. Excessive toxicity when treating central tumors in a phase II study of stereotactic body radiation therapy for medically inoperable early-stage lung cancer. J Clin Oncol. 2006;24:4833-9.

24. Takeda A, Kunieda E, Takeda T, Tanaka M, Sanuki N, Fujii H, Shigematsu $\mathrm{N}$, Kubo A. Possible misinterpretation of demarcated solid patterns of radiation fibrosis on $\mathrm{CT}$ scans as tumor recurrence in patients receiving hypofractionated stereotactic radiotherapy for lung cancer. Int J Radiat Oncol Biol Phys. 2008;70:1057-65.

\section{Publisher's Note}

Springer Nature remains neutral with regard to jurisdictional claims in published maps and institutional affiliations.
Ready to submit your research? Choose BMC and benefit from:

- fast, convenient online submission

- thorough peer review by experienced researchers in your field

- rapid publication on acceptance

- support for research data, including large and complex data types

- gold Open Access which fosters wider collaboration and increased citations

- maximum visibility for your research: over $100 \mathrm{M}$ website views per year

At BMC, research is always in progress.

Learn more biomedcentral.com/submissions 